\title{
Self-expressiveness in shopping
}

\section{Joseph Sirgy ${ }^{\mathrm{a}, *}$, Dong-Jin Lee ${ }^{\mathrm{b}}$, Grace B. Yu $^{\mathrm{c}}$, Eda Gurel-Atay ${ }^{\mathrm{d}}$, John Tidwell ${ }^{\mathrm{e}}$, Ahmet Ekici ${ }^{\mathrm{f}}$}

a Virginia Polytechnic Institute E' State University, Department of Marketing, Blacksburg, VA 24061-0236, USA

${ }^{\mathrm{b}}$ Yonsei University, School of Business, Seodaemun-gu, Seoul 120-749, South Korea

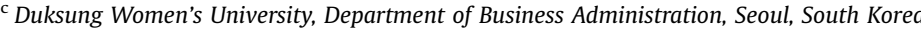

${ }^{\mathrm{d}}$ Independent Researcher, Redmond, WA 98052, USA

e American Chemical Society, Washington, DC 20036, USA

${ }^{\mathrm{f}}$ Bilkent University, Faculty of Business Administration, Bilkent, 06800 Ankara, Turkey

\section{A R T I C L E I N F O}

\section{Article history:}

Received 16 February 2016

Accepted 18 February 2016

Available online 10 March 2016

Keywords:

Self-expressiveness in shopping

Perceived impact of shopping on overall life satisfaction

Life satisfaction

\begin{abstract}
A B S T R A C T
Some people experience self-expressiveness in shopping. Self-expressiveness in shopping is defined as the degree to which consumers they think shopping activity is an important part of their self-concept. This paper reports on the testing of a model dealing with antecedents and consequences of self-expressiveness in shopping. Based on eudaimonistic identity theory, we hypothesized that feeling of self-expressiveness in shopping is influenced by consumers' flow experiences in shopping activities, self-realization potential through shopping, and effort expended through shopping. We also hypothesize that self-expressiveness in shopping increases overall life satisfaction, mediated by perceived impact of shopping on life satisfaction. The model was tested using a panel of 5440 shoppers. The results provide good support for the model. Managerial implications are discussed in addition to avenues for future research.
\end{abstract}

(c) 2016 Elsevier Ltd. All rights reserved.

\section{Introduction}

Consider the following scenario. The consumer is a traditional housewife living in a rural area; let's call her Amina. She is a mother of four children of varying ages. Her husband is gainfully employed and leaves all household affairs to his wife. Amina thinks of herself as a good housewife and a mother. She takes her household duties very seriously. She has a family to take care of. Every morning she goes to the farmer's market to buy fresh vegetables. At the farmer's market she engages the merchants. She asks about prices, the freshness of their produce and meat. Amina bargains with the merchants and closely inspects the produce and meat for freshness and other quality features. She wants the best for her family. Her shopping activity reflects her self-concept-her personal identity of being a good housewife and mother. She enjoys her daily shopping routine. It makes her happy. She feels that her shopping is an important task in meeting her family needs while ensuring that the family's budget is not compromised. She feels that what she does contributes to the quality of her life and her family. She shops frequently. Her identity is closely tied with

\footnotetext{
* Corresponding author.

E-mail addresses: sirgy@vt.edu (M.J. Sirgy),djlee81@yonsei.ac.kr (D.-J. Lee) byungheeyu@duksung.ac.kr (G.B. Yu), edagurel@gmail.com (E. Gurel-Atay), john.tidwell@mac.com (J. Tidwell), ekici@bilkent.edu.tr (A. Ekici).
}

her daily shopping routine. This may be due to the fact that she invests a great deal of time and effort in shopping; she feels that shopping is an important task (perhaps a duty) in her life overall; she perceives that shopping is a way in life to realize her potential as a good housewife and mother; and that when shopping she feels truly engaged and becomes totally absorbed in the activity.

Consumers engage in shopping, some are extrinsically motivated while others are intrinsically motivated (Shah and Kruglanski, 2000). Extrinsically-motivated shoppers engage in shopping simply to acquire the needed items. In contrast, intrinsicallymotivated shoppers engage in shopping to experience fun or to express their shopping competence. Intrinsically-motivated shoppers view shopping as an important self-defining activity and shopping is a salient component to their personal identity (Guiry et al., 2006; Shim and Dubey, 1995). In other words, they experience feelings of being alive and fulfilled. They experience self-expressiveness, which in turn contribute to their overall life satisfaction (cf. Waterman, 1990, 1993).

This paper reports a study that focuses on self-expressiveness in shopping. The concept of self-expressiveness in shopping is defined as the degree to which consumers think shopping activity is an important part of their self-concept. Individuals experience self-expressiveness in any activity when the activity allows them to engage in meaningful and self-defining ways that lead to actualization of one's potentials (Waterman, 1993; Waterman et al., 
2008). Translated in a shopping context, self-expressiveness in shopping is a state of mind shoppers experience when they engage in shopping in meaningful and self-defining ways that lead to actualization of one's potential.

Although past research have examined hedonic shopping (e.g., Anderson et al., 2014; BäckströmK, 2011; Carpenter and Moore, 2009) and shopping associated with the consumption of personally meaningful and socially expressive products, there is sparse research on self-expressiveness in shopping. Specifically, we have a limited understanding on how self-expressiveness in shopping influence consumers' overall life satisfaction. The current study is an attempt to fill this gap. Specifically, the study examines the antecedents and consequences of self-expressiveness in shopping.

Knowing more about self-expressiveness in shopping (e.g., how it is formed and how it affects consumers) can help us better understand the well-being implications of shopping activities (cf. El-Hedhli et al., 2013; Wagner, 2007). Knowing more about feelings of self-expressiveness in shopping should help retailers develop shopping environments that could help form and reinforce self-expressiveness in shopping and, hence, the well-being of consumers.

Accordingly, the purpose of this study is to better understand the social psychological mechanics underlying self-expressiveness in shopping. More specifically, we will examine antecedents and consequences of self-expressiveness in shopping in a nomological network. In other words, the study will examine factors affecting formation of self-expressiveness in shopping such as shopping flow, self-realizing through shopping, and effort expended in shopping. Additionally, the study will examine the impact of selfexpressiveness in shopping on perceived impact of shopping on life satisfaction and overall life satisfaction.

\section{Conceptual development}

We start this section by discussing eudaimonistic identity theory and how the theory is used to articulate the concept of selfexpressiveness in shopping. We then discuss antecedents and consequences of self-expressiveness in shopping.

\subsection{Eudaimonistic identity theory}

Eudaimonistic identity theory argues that engaging in activities that induce self-expressiveness are likely to increase overall life satisfaction and happiness (Waterman, 1990, 1993; Waterman et al., 2008; p. 6). Based on this theory, there are two types of activities that may contribute to subjective well-being: activities that lead to hedonic enjoyment alone and activities that lead to both hedonic enjoyment and self-expressiveness. The former is referred to as "hedonically enjoyable activities," while the latter is "self-expressive activities" (Waterman, 1990; Waterman et al., 2008).

People engaging in self-expressive activities are likely to experience a higher level of life satisfaction and happiness than those who do not engage in such activities. They are likely to experience strong feelings of being alive and being fulfilled while engaging in self-expressive activities because these activities are meaningful and intrinsically rewarding for their personal development. While engaging in self-expressive activities, individuals experience satisfaction of psychological needs such as autonomy, competence, and relatedness, which in turn contributes to one's life satisfaction and happiness (cf. Deci et al., 2001). Thus, engaging in self-expressive activities contributes to life satisfaction and happiness. Past research have shown that self-expressiveness is highly correlated with concepts such as flow, intrinsic motivation, and realization of one's potential (Waterman, 1993; Waterman et al., 2008).

\subsection{Self-expressiveness in shopping}

The notion of self-expressiveness can be discussed in terms of activity characteristics such as self-expressive activities vs. hedonic activities, or the degree to which an individual experience feelings of self-expressiveness while engaging in the activity. In this study, we focus on self-expressiveness consumers experience while engaging in shopping.

Self-expressiveness is a subjective state associated with engaging in intrinsically motivated, identity-related activities (Waterman, 1990). Specifically, self-expressiveness in shopping is defined as the degree to which consumers think shopping activity is an important part of their self-concept perceiving themselves as making progress towards the realization of their best potential through shopping. In generic terms, individuals experience selfexpressiveness when they engage in meaningful and self-defining activities that lead to actualization of one's potentials (Waterman, 1993; Waterman et al., 2008).

It is important to make a conceptual distinction between selfexpressiveness and hedonic enjoyment (Waterman, 1993; Waterman et al., 2008). Self-expressiveness and hedonic enjoyment are considered as two distinct concepts of happiness (Waterman, 1993). Hedonic enjoyment is positive affect that accompanies getting or having the material object and action opportunity one wishes to possess or to experience. That is, it is a pleasant feeling that goes with the belief that one is getting important things one wants (Waterman et al., 2008). Activities that induce self-expressiveness also provide hedonic enjoyment. It should be noted that self-expressiveness is a sufficient, but not a necessary condition for hedonic enjoyment (Telfer, 1980). Activities that provide hedonic enjoyment do not always induce self-expressiveness. In other words, there are many activities that give rise to hedonic enjoyment, but not self-expressiveness (Waterman, 2008). Research has shown that self-expressiveness have an enduring effect on one's life satisfaction while feeling of hedonic enjoyment has an ephemeral, temporary effect on one's life satisfaction.

\subsection{A model of self-expressiveness in shopping}

Fig. 1 shows the conceptual model of this study. Guided by eudaimonistic identity theory, the model posits that self-expressiveness in shopping is mostly determined by consumers' flow experience in shopping, self-realization through shopping, and effort expended in shopping (cf. Csikszentmihalyi, 1997; Csikszentmihalyi and Csikszentmihalyi, 1992). The model also posits that self-expressiveness in shopping has a positive influence on perceived impact of shopping on life satisfaction and overall life satisfaction.

\subsubsection{Flow experience in shopping and self-expressiveness in shopping}

Flow is defined as the "process of optimal experience" (Csikszentmihalyi and LaFevre, 1989; p. 816). People who experience the

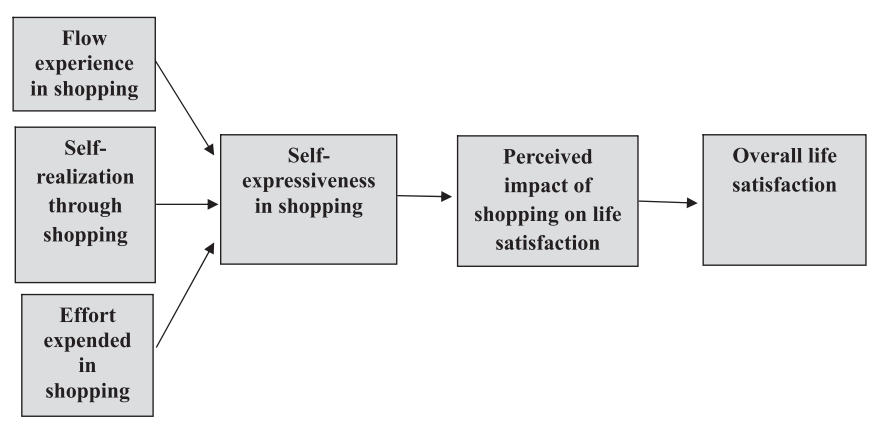

Fig. 1. A model of self-expressiveness in shopping. 
flow when engaging in an activity (1) find that activity intrinsically enjoyable, (2) are highly involved with the activity, (3) experience a loss of self-consciousness, (4) focus their attention completely on the activity, and (5) lose the track of the time (Csikszentmihalyi, 1997; Hoffman and Novak, 1996). Consumers experiencing flow in shopping are likely to find that shopping is intrinsically enjoyable, become totally absorbed in the act of shopping, and feel that time stands still while shopping (Hoffman and Novak, 1996).

Consumer's flow experience in shopping activity reflects a special fit or meshing with the shopping activities. This flow experience in shopping activities may facilitate consumer's selfawareness and leads them to believe that the shopping activity is important in defining who they are (cf. Csikszentmihalyi, 1990; Sharp et al., 2007). Thus, flow experience in shopping is likely to heighten self-expressiveness in shopping because the flow experience may facilitate the perception that shopping is an enjoyable self-defining activity (cf. Waterman, 1990, 1993; Waterman et al., 2008). Based on the discussion, we hypothesize the following.

H1. Self-expressiveness in shopping is a positive function of the experience of flow while shopping. That is, when consumers experience a high level of flow in shopping, they are likely to experience self-expressiveness in shopping too.

\subsubsection{Self-realization potential through shopping and self-expres- siveness in shopping}

One of the principles of eudaimonistic identity theory (Waterman, 1990, 1993; Waterman et al., 2008) is the notion that an activity perceived to have the potential for self-realization contributes to self-expressiveness in that activity. Perception of selfrealization of an activity refers to the degree to which the activity provides the opportunity to make progress towards one's life goals (Waterman, 1993).

Perception of self-realization of an activity increases the feelings of self-expressiveness while engaging in the activity. When consumers perceive shopping as having potential for self-realization, they may be intrinsically motivated to engage in that activity to attain personally meaningful goals (cf. Waterman et al., 2008). Making progress towards personally meaningful goals makes the activity more self-expressive (Waterman, 1993). There is empirical evidence that suggests that an activity perceived to have the potential for self-realization contributes to self-expressiveness in that activity (Waterman, 1990, 1993; Waterman et al., 2008). Based on the discussion, the following hypothesis will be tested:

H2. Self-expressiveness in shopping is a positive function of perceived potential for self-realization through shopping. That is, when consumers perceive a high potential for self-realization through shopping, they are likely to experience high levels of self-expressiveness in shopping too.

\subsubsection{Effort expended in shopping and self-expressiveness in shopping}

Self-expressiveness in an activity is partly determined when people perceived they are making progress towards the goal of self-realization through that activity (Waterman, 1993). Individuals have the perception of making progress towards selfrealization when they expend much time and effort on that activity (Csikszentmihalyi and Csikszentmihalyi, 1992; Waterman, 2005). Research has documented the fact that self-expressiveness in an activity increases with increases in effort on that activity (Waterman, 2005). Thus, one can argue that feelings of self-expressiveness in shopping are likely to increase when consumers spend much time and effort in shopping-making progress in attaining personally meaningful goals. Based on this discussion, we hypothesize the following:

H3. Self-expressiveness in shopping is a positive function of effort spent in shopping. That is, when consumers spend a significant amount of effort in shopping, they are likely to experience high levels of self-expressiveness in shopping too.

\subsubsection{Self-expressiveness in shopping and perceived impact of shopping on life satisfaction}

As previously mentioned, self-expressiveness in an activity reflects a belief that the activity is an important self-defining activity (Waterman, 1990, 1993; Waterman et al., 2008). When consumers experience self-expressiveness in shopping they are likely to experience a high level of enjoyment while shopping. Eudaimonistic identity theory (Waterman, 1990, 1993; Waterman et al., 2008) suggests that activities that are self-expressiveness contribute to one's overall life satisfaction and happiness. This is because self-expressiveness of an activity provides one with hedonic enjoyment as well as experience of self-actualization through the fulfillment of one's potential. As such, we believe that self-expressiveness in shopping is likely to induce a positive perception of shopping impact on life satisfaction. Specifically, we define perceived impact of shopping on life satisfaction as the degree to which consumers perceive that shopping contributes to their overall life satisfaction. The perception that shopping contributes to their well-being is also referred to as "shopping well-being" (ElHedhli et al., 2013).

Let's explain the relationship between self-expressiveness in shopping and perceived impact of shopping on life satisfaction in more detail. We believe that a consumer's self-expressiveness in shopping have a positive influence on consumer's perceived impact of shopping on life satisfaction due to the following reasons.

First, consumer's self-expressiveness in shopping may lead consumers to experience positive affect while engaging in shopping (cf. Bosnjak et al., 2016). As self-expressive activities are activities that are both personally meaningful and hedonically enjoyable, consumers are likely to experience a warm glow or good feeling while engaging in the self-expressive activity (cf. Waterman, 1993). Those consumers who experience self-expressiveness in shopping are likely to experience a high degree of positive affect from shopping (cf. Arnold and Reynolds, 2003; Babin et al., 1994; Guiry et al., 2006; Hirschman, 1984; Wakefield and Baker, 1998).

Second, consumers high on self-expressiveness in shopping are likely to view shopping as a personally relevant and important activity in achieving their personal goals (Swinyard, 1993). They are likely to perceive the consumer-market life as an important life domain affecting their overall life satisfaction (cf. Rojas, 2006).

Third, one can argue that shopping has a negative influence on one's life satisfaction as in the case of impulsive buying, compulsive shopping(e.g., Kwak et al., 2003; Roberts et al., 2003; Roberts and Tanner, 2005) and/or materialism (e.g., Burroughs and Rindfeisch, 2002; Richins and Dawson, 1992; Sirgy et al., 2013). We argue that compulsive shopping is not likely to be associated with self-expressiveness in shopping because such behavior is detrimental to personal development and the actualization of one's best potentials. Compulsive shopping may be hedonically enjoyable but has very little to do with self-expressiveness. Self-expressive activities, by definition, are activities associated with personal growth, fulfillment, and development (Waterman, 1993). Impulsive buying is a spontaneous and unreflective buying behavior driven by immediate gratification (Rook and Fisher, 1995). Research has shown that impulsive buying has a negative influence on subjective well-being (e.g., Silvera et al., 2008). Materialism is a set of centrally held beliefs about the importance of 
possessions in life (Richins and Dawson, 1992). Research has shown that materialistic individuals report lower levels of life satisfaction and self-actualization than their non-materialistic counterparts (Richins and Dawson, 1992), lower levels of happiness (Belk, 1985), and higher levels of depression (Kasser and Ryan, 1993).

Individuals experience self-expressiveness when they engage in meaningful and self-defining activities that lead to actualization of one's potentials (Waterman, 1993). Consumers with high levels of self-expressiveness in shopping are likely to experience positive affect and enjoyment while shopping. At the same time, they are likely to view shopping as an important and meaningful activity contributing to realization of their true self. Thus, the self-expressive shoppers' positive affect and perceived importance of shopping may lead then to infer that shopping significantly contributes to their overall life satisfaction. Hence, one can argue that self-expressiveness in shopping is likely to have a positive influence on consumer's perceived impact of shopping on life satisfaction. Based on the discussion, we hypothesize the following:

H4. Perceived shopping impact on life satisfaction is a positive function of self-expressiveness in shopping. That is, when consumers perceive shopping to be an important part of their identity they are likely to perceive that shopping contributes meaningfully to their life satisfaction.

\subsubsection{Perceived impact of shopping on life satisfaction and overall life satisfaction}

Overall life satisfaction is determined by a host of factors including top-down factors (i.e., personality factors such as optimism, neuroticism, self-esteem, and extraversion), and bottom-up factors (i.e., situational factors such as satisfaction with specific life events) (Diener, 1984; Diener et al., 1999; Sirgy, 2012). Consumers who believe that shopping does contribute significantly to their satisfaction with life overall are likely to experience a higher level of life satisfaction than those who do not have this belief. This may be due for the following reasons. First, consumers with a high level of perceived impact of shopping on life satisfaction are likely to experience positive affect in the consumermarket life domain (Davis and Hodges, 2012) and this positive affect is likely to horizontally spill over to other neighboring life domains such as leisure life, social life, family life, and financial life. This assertion is supported by horizontal spillover theory of life satisfaction, which states that overall life satisfaction is not only determined by satisfaction in salient life domains but also from the spillover of affect across these salient domains (Sirgy, 2012; pp. 246-249).

Second, consumers with a high level of perceived impact of shopping on life satisfaction are likely to experience positive affect in the consumer-market life domains, which is likely to vertically spillover to overall life satisfaction, especially given the fact that such consumers may perceive consumer life to be a salient life domain define their personal identity. When consumers think that shopping is an important part of their lives, their affective experiences of shopping enjoyment from this self-expressive activity are likely to influence overall life satisfaction. This hypothesis is supported by bottom-up vertical spillover theory of life satisfaction, which states that overall life satisfaction is determined by satisfaction in salient life domains such as family life, social life, work life, love life, financial life, spiritual life, among others (Sirgy, 2012; pp. 240-246). Based on this discussion, the following hypothesis will be tested:

H5. Overall life satisfaction is a positive function of perceived shopping impact on life satisfaction. That is, consumers who perceive that shopping does make a significant and positive impact of their life satisfaction are likely to report high levels of life satisfaction in general too.

\section{Method}

\subsection{Sampling and data collection}

To test the conceptual model shown in Fig. 1, data were collected from 5440 adult consumers through an internet-based national survey conducted in the United States. CivicScience, a marketing research firm, collected the data. Out of 5440 respondents who participated in the survey, 2085 (38.3\%) were males and 3355 (61.7\%) were females. The age distribution by the shopping frequency distribution is shown in Table 1 . The results in the table show a great deal of variance in both age and shopping frequency. This finding gives confidence in generalizing the study findings to the consumer population at large.

\subsection{Survey procedure}

We used the following survey procedure to minimize method bias. The survey questionnaire was administered in several waves. Survey respondents were asked to respond to survey items at different times in different settings. Once the data collection was completed, data pertaining to specific survey respondents across these different times and settings were assembled to build the final data file used in the statistical analysis.

Specifically, the global marketing research firm, CivicScience, designed this data collection method. The process is intended to reduce respondent fatigue, increase response rates, and limit fraudulent responses.

The CivicScience method administers the survey questionnaire in several waves using a polling widget hosted on more than 450 third-party websites. The sites include: newspapers, blogs, social media sites, TV networks, and others. The survey method engaged respondents who opted-in to answer a fun poll question as part of the three-question set. Upon answering the fun question, respondents were presented with one of the study's measurement items. This was followed by a profile question (demographic item). Once they completed the three items, they were then shown the current results for those items (i.e., cumulative survey results across all survey respondents across all sites). Showing the current results for the completed survey items serves as an intrinsic incentive for respondents (such as comparing themselves to peers or learning interesting insights about themselves). Respondents could choose to answer more questions at that time or not. Respondents not choosing to complete the survey in one sitting would be given additional portions of the survey when they visited another third-party website.

Respondents were identified and tracked by a unique and anonymous digital alias that included a browser cookie, IP address,

Table 1

Sample characteristics $(n=5440)$.

\begin{tabular}{llrl}
\hline & & $n$ & $(\%)$ \\
\hline \multirow{2}{*}{ Gender } & Male & 2085 & $(38.3)$ \\
\multirow{3}{*}{ Age } & Female & 3355 & $(61.7)$ \\
& Under 18 & 74 & $(1.4)$ \\
& $18-24$ & 392 & $(7.2)$ \\
& $25-34$ & 393 & $(13.7)$ \\
& $35-44$ & 942 & $(17.3)$ \\
& $45-54$ & 1494 & $(27.5)$ \\
& $55-64$ & 1320 & $(24.3)$ \\
& 65 or older & 469 & $(8.6)$ \\
\hline
\end{tabular}


and other available respondent specific items like Facebook Connect ID or the user login ID from a logged-in website. The digital alias allows CivicScience to identify and track individual respondents over multiple visits across multiple sites, append responses from multiple polls to build a longitudinal profile, and ensure that respondents do not answer the same question more than once. Furthermore, the alias enables the targeting of specific respondent types, and/or respondent locations. These data ensure reliability and consistency in future data collection for others replicating an investigation.

In addition to tracking, a series of algorithms were used to identify conflicting combinations of answers in a respondent's profile. Through these algorithms, multiple users on the same computer were identified and removed from the dataset. Once the data collection was completed, data pertaining to specific survey respondents across different times and settings were assembled to build the final data file used in the statistical analysis.

\subsection{Constructs and measures}

For all constructs, items were adopted from well-established measures to ensure high measurement reliability and validity.

Self-expressiveness in shopping was measured by using items adopted from Waterman (1990) and Sivadas and Machleit (1994), and these items were modified to reflect the extent shopping helps people express themselves $(\alpha=.990)$. The survey items were: (1) "Shopping gives me the greatest feeling of really being alive," (2) "When I do my shopping I feel more intensely involved than I do when engaged in most other activities," (3) "Shopping gives me my strongest feeling that this is who I really am," (4) "When I do my shopping I feel this is what I was meant to do," (5) "I feel more complete or fulfilled when doing shopping than I do when engaged in most other activities," (6) "I feel a special fit or meshing when doing shopping," (7) "My shopping is central to my identity," and (8) "My shopping is part of who I am." The response scale used for these survey items was a 7-point Likert-type scale: $1=$ "strongly disagree"; $7=$ =strongly agree."

Two or three items were used to measure each of the antecedents of self-expressiveness in shopping. Items capturing flow in shopping ( $\alpha=.860$ ) were: (1) "When I do my shopping, I feel in control" (reverse-coded), (2) "When I do my shopping, I lose track of time," (3) "When I do my shopping, I feel very concentrated in the shopping activity." A 7-point Likert-type scale was used to capture responses to these items: $1=$ "strongly disagree"; $7=$ "strongly agree."

Items capturing self-realization through shopping $(\alpha=.981)$ were: (1) "Shopping provides me the opportunity to realize the best that I can be," (2) "Shopping provides me with the opportunity to achieve goals that are important in my life." A 7-point Likert-type scale was used to capture responses to these items: $1=$ "strongly disagree"; 7 ="strongly agree."

Items capturing effort expended in shopping ( $\alpha=.977)$ were: ( 1$)$ "I invest much effort in my regular shopping," (2) "I put a lot of time and effort every time I go shopping." A 7-point Likert-type scale was used to capture responses to these items: $1=$ "strongly disagree"; $7=$ "strongly agree." Please note that these measures were adopted from Waterman (1993) but modified to reflect a shopping context.

The perceived impact of shopping on life satisfaction construct was captured through a set of items borrowed and adapted from past studies involving "consumption happiness" (Nicolao et al., 2009; Van Boven and Gilovich, 2003). The reliability was high: $\alpha=.986$. The survey items were: (1) "Thinking about shopping, I feel that my shopping contributes significantly to my own and my family's well-being," (2) "Thinking about shopping, my quality of life would diminish significantly if I don't shop," (3) "Thinking about shopping, I feel that shopping makes me happy," and (4) "Thinking about shopping, I feel that shopping contributes significantly to my quality of life overall." A 7-point Likert-type scale was used to capture responses to these items: $1=$ "strongly disagree"; $7=$ "strongly agree."

Similarly, four items from the Satisfaction with Life Scale (Pavot and Diener, 2008) were adopted to measure overall life satisfaction ( $\alpha=.984$ ). The survey items were: (1) "I believe that in most ways my life is close to my ideal," (2) "I think that the conditions in my life are excellent," (3) "I believe that I am satisfied with my life," (4) "I can say that so far I have gotten the important things I want in life." A 7-point Likert-type scale was used to capture responses to these items: $1=$ "strongly disagree"; 7 ="strongly agree."

\section{Results}

The two-step model suggested by Anderson and Gerbing (1988) was used to estimate the measurement model in the first step and the structural model in the second step. LISREL 8.80 was used to analyze the covariance matrices in these analyses.

\subsection{Measurement model}

We assessed reliability and validity using confirmatory factor analysis. The results are reported in Table 2 and suggest that our measurement model provides a good fit for the data $\left[\chi^{2}(p\right.$ value $)=6242.013(.00), d f=103, \mathrm{CFI}=0.968, \mathrm{NFI}=0.968, \mathrm{NNFI}=$ $0.953, \mathrm{GFI}=0.900, \mathrm{RMSEA}=0.099, \mathrm{SRMR}=0.026]$

As evidence of convergent validity, the confirmatory factor analysis results indicate that all items are significantly related to their hypothesized factors without high cross-loadings $(p<0.01)$. To demonstrate convergent validity, the average variance extracted (AVE) for each construct should be greater than .50 and the composite reliability of a factor should be equal to or greater than .60 (Fornell and Larcker, 1981). All AVE values ranged from .939 to .982. Composite reliabilities were greater than .60 with a range of .937-.990. Similarly, alpha coefficients were high with a range of .860 to .990 . All these results imply that convergent validity was satisfactory for the constructs in question.

Evidence for the discriminant validity of the measures was provided in three ways. First, none of the $95 \%$ confidence intervals of the individual elements of the phi-matrix $(\phi$, or the correlation matrix of the latent constructs) contained a correlation of 1.0. Second, a series of Chi-squared difference tests was conducted for each pair of constructs between the constrained model $\left(\phi_{i j}=1.0\right)$ and the unconstrained model. In all cases, the unconstrained model provided a significantly better fit for the data than did the constrained model $(p<0.01)$. Third, the AVE for each construct was greater than its squared correlation with any other construct. The results in Table 3 provide support for the convergent and discriminant validity of the measures used in the study. In sum, the results of convergent and discriminant validity tests provided evidence for the construct validity of the measures used in this study.

\subsection{Test of common method bias}

As all the data were perceptual and we collected from the same source, there is a possibility of common method bias. We examined the potential common method bias. Three models were estimated. M1 was a the method-only model in which all items were loaded on one factor $\chi_{(118)}^{2}=74,572, \mathrm{p}=0.000 ; \mathrm{CFI}=0.616$, $\mathrm{GFI}=0.493$, RMSEA $=0.280$ ); M2 was a trait-only model in which each item was loaded on its respective scale $\left(\chi_{(103)}^{2}=6242\right.$; $\mathrm{CFI}=0.968, \mathrm{GFI}=0.900, \mathrm{RMSEA}=0.099) ; \mathrm{M} 3$ was a trait and 
Table 2

Confirmatory factor analysis for the measurement model.

\begin{tabular}{|c|c|c|c|c|c|c|}
\hline Construct & Indicator & Factor loading & t-value & Cronbach alpha & AVE & Composite reliability \\
\hline \multirow[t]{2}{*}{ Flow } & Flow 1 & 0.934 & 88.678 & 0.860 & 0.939 & 0.937 \\
\hline & Flow 2 & 0.943 & 89.604 & & & \\
\hline \multirow[t]{2}{*}{ Self-realization } & Realization 1 & 0.994 & 103.611 & 0.981 & 0.982 & 0.981 \\
\hline & Realization 2 & 0.969 & 98.396 & & & \\
\hline \multirow[t]{2}{*}{ Effort } & Effort 1 & 0.949 & 93.761 & 0.977 & 0.971 & 0.970 \\
\hline & Effort 2 & 0.992 & 104.499 & & & \\
\hline \multirow[t]{6}{*}{ Self-expressiveness in shopping } & Express 1 & 0.964 & 97.959 & 0.990 & 0.968 & 0.990 \\
\hline & Express 2 & 0.960 & 97.683 & & & \\
\hline & Express 3 & 0.979 & 101.163 & & & \\
\hline & Express 4 & 0.968 & 98.740 & & & \\
\hline & Express 5 & 0.978 & 100.748 & & & \\
\hline & Express 6 & 0.976 & 100.547 & & & \\
\hline \multirow[t]{3}{*}{ PISLS } & PISLS 1 & 0.969 & 98.348 & 0.986 & 0.975 & 0.983 \\
\hline & PISLS 2 & 0.987 & 101.825 & & & \\
\hline & PISLS 3 & 0.968 & 98.207 & & & \\
\hline \multirow[t]{3}{*}{ Life satisfaction } & LS 1 & 0.980 & 101.288 & 0.984 & 0.978 & 0.985 \\
\hline & LS 2 & 0.977 & 101.306 & & & \\
\hline & LS 3 & 0.976 & 100.499 & & & \\
\hline
\end{tabular}

Fit Indices: $\chi^{2}(p$-value $)=6242.013(.00), d f=103, \mathrm{CFI}=0.968, \mathrm{NFI}=0.968, \mathrm{NNFI}=0.953, \mathrm{GFI}=0.900, \mathrm{RMSEA}=0.099, \mathrm{SRMR}=0.026$.

Note. PISLS $=$ Perceived Impact of Shopping on Life Satisfaction.

Table 3

Correlations among the constructs.

\begin{tabular}{llllllll} 
& a & b & c & d & e & f \\
\hline Flow (a) & 1.000 & & & & & \\
Self-realization (b) & 0.680 & 1.000 & & & & \\
Effort (c) & 0.599 & 0.683 & 1.000 & & & \\
Self-expressiveness in shopping & 0.565 & 0.813 & 0.675 & 1.000 & & \\
$\quad(d)$ & & & & & & \\
PISLS (e) & 0.625 & 0.779 & 0.690 & 0.781 & 1.000 & \\
Life satisfaction (f) & 0.158 & 0.181 & 0.183 & 0.151 & 0.208 & 1.000 \\
\hline
\end{tabular}

Notes: PISLS = Perceived Impact of Shopping on Life Satisfaction

method model in which a common factor linking to all the measurement items was added into $\mathrm{M} 2\left(\chi_{(79)}^{2}=3483 ; \mathrm{CFI}=0.982, \mathrm{GFI}=\right.$ 0.938, RMSEA $=0.085)$. Comparing these three models, M3 and M2 showed a much better fit than M1 to the data. Although M3 has a better fit than $\mathrm{M} 2$, the trait rather than the common method factor explains most of the variance. These results suggest that common method bias is not a threat in this study.

\subsection{Structural model}

The structural model was used to test hypotheses 1-5 (H1-H5). The results are summarized in Table 4. The overall structural model was supported by the data: $\chi^{2}(p$-value $)=6430(.00)$, $d f=109, \quad \mathrm{CFI}=0.967, \quad \mathrm{NFI}=0.967, \quad \mathrm{NNFI}=0.954, \quad \mathrm{GFI}=0.894$, RMSEA $=0.098, S R M R=0.032$. Furthermore, all path coefficients were significant at the .01 level (see Table 4).

Table 4

Test of the hypothesized relationships.

\begin{tabular}{lll}
\hline Relationships & Standardized estimate \\
\hline H1 & Flow $\rightarrow$ Self-expressiveness in shopping & $0.027^{* * *}$ \\
H2 & Self-realization $\rightarrow$ Self-expressiveness in & $0.618^{* * *}$ \\
shopping & \\
H3 Effort $\rightarrow$ Self-expressiveness in shopping & $0.250^{* * *}$ \\
H4 Self-expressiveness in shopping $\rightarrow$ PISLS & $0.978^{* *}$ \\
H5 & PISLS $\rightarrow$ Life Satisfaction & $0.208^{* * *}$ \\
\hline
\end{tabular}

Fit Indices: $\chi^{2}(p$-value $)=6430.605(.00), d f=109$,

$\mathrm{CFI}=0.967, \mathrm{NFI}=0.967, \mathrm{NNFI}=0.954, \mathrm{GFI}=0.894, \mathrm{RMSEA}=0.098, \mathrm{SRMR}=0.032$.

Notes: PISLS = Perceived Impact of Shopping on Life Satisfaction.

** Significant at $95 \%$ confidence interval.
All three antecedents of self-expressiveness in shopping (i.e., flow experiences, self-realization potential, and effort investment in shopping) had significant and positive impact on self-expressiveness in shopping, providing support for H1, H2, and H3. Specifically, self-expressiveness in shopping was positively and significantly predicted by flow experiences in shopping (standardized estimate $=.027, p<.01$ ), perception of self-realization potential through shopping (standardized estimate $=.618, p<.01$ ), and perceived effort expended in shopping (standardized estimate $=.250, p<.01$ ). Taken together, these three antecedents explained $65 \%$ of the variance in self-expressiveness in shopping.

The results also indicate that self-expressiveness in shopping increases overall life satisfaction, mediated by perceived shopping's impact on life satisfaction. Specifically, self-expressiveness in shopping had a positive and direct predictive effect on perceived impact of shopping on life satisfaction (standardized estimate $=.978, p<.01$ ), supporting $\mathrm{H} 4$. In addition, the results indicate that perceived impact of shopping on life satisfaction had a positive effect on overall life satisfaction (standardized estimate $=.208, p<.01$ ). These results provide support for $\mathrm{H} 4$ and H5.

The conceptual model posits the effect of self-expressiveness in shopping on overall life satisfaction, mediated by perceived impact of shopping on life satisfaction. In order to test these mediation effects, a Sobel test was conducted. The results are summarized in Fig. 2. The results indicate that the effect of self-expressiveness in shopping on overall life satisfaction is fully mediated by perceived impact of shopping on life satisfaction $(t=7.556, p<0.01)$.

\section{Discussion}

This research makes several contributions to the consumer research and quality-of-life literature by testing a model of selfexpressiveness in shopping. Based on the literature of eudaimonistic identity theory (e.g., Waterman, 1993), this study shows that flow experiences, perception of self-realization potential, and effort in shopping are the key determinants of selfexpressiveness in shopping. To the best of our knowledge, this is the first study that formally tests the effect of self-expressiveness in shopping on shopper's overall life satisfaction. The study shows that perceived impact of shopping on life satisfaction (or shopping well-being) does indeed contribute to life satisfaction. 


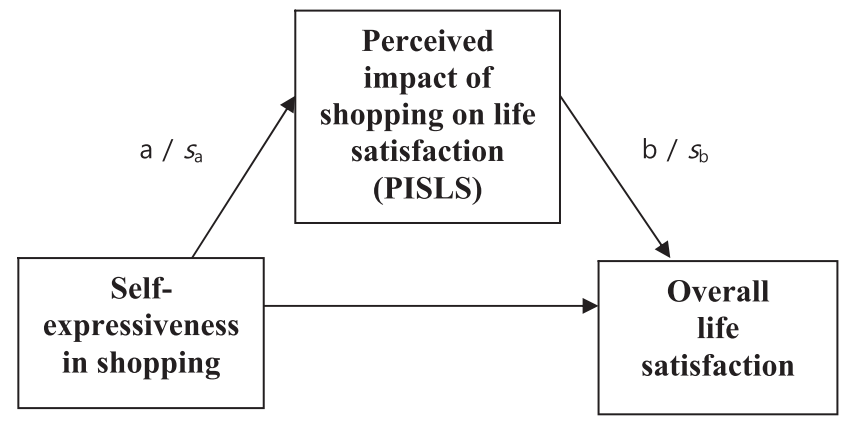

\begin{tabular}{|c|c|c|c|}
\hline $\mathbf{a} / \boldsymbol{s}_{\mathbf{a}}$ & $\mathbf{b} / \boldsymbol{s}_{\mathbf{b}}$ & Test statistic & p-value \\
\hline $0.659(0.008)$ & $0.129(0.017)$ & $7.556^{* *}$ & 0.000 \\
\hline
\end{tabular}

Fig. 2. Test of mediation effect: Sobel test. Notes: $a=$ raw (unstandardized) regression coefficient for the association between IV and mediator. $s_{\mathrm{a}}=$ standard error of $a$. $b=$ raw coefficient for the association between the mediator and the DV (when the IV is also a predictor of the DV). $s_{\mathrm{b}}=$ standard error of $b .{ }^{* *}$ significant at $p<0.05$.

The managerial implications of the present study are straight forward. Store managers, for example, can contribute to consumers' perception of shopping impact on life satisfaction and overall life satisfaction by developing strategies that enhance selfexpressiveness in shopping. These strategies should be designed to increase flow experiences in shopping activities, perception of self-realization through shopping, and effort in shopping activities. First, this study found that consumer's experiences of flow during shopping increases self-expressiveness in shopping. In order to increase the flow experiences in shopping activities, an exciting environment that encourages browsing, product comparisons, and spending time should be designed. Retail managers should make an effort to provide shoppers with enjoyable shopping experiences (cf. El-Hedhli et al., 2013). Second, this study found that consumer's perception of self-realization potential increases self-expressiveness in shopping. To increase the perceived potential for selfrealization through shopping, retailers can emphasize the personal relevance of shopping to personal well-being. Advertising can be a very powerful tool here. Ads can show how shopping can make consumers feel good about their selves. Please note that the emphasis here should not be on acquisition of material goods; the focus should be on the act of shopping. Third, this study found that effort in shopping increase self-expressiveness in shopping. However, strategies to increase effort in shopping should focus on the activities that improve the shopping outcomes of consumers instead of the activities that lead to waste of time. For instance, a maze of aisles that makes locating products difficult may increase the time and effort spent by shoppers but it can also lead to distress and discomfort. On the other hand, in-store signage, in-store customer service, self-service technology (e.g., store GPS units, kiosks, price check machines, computers to compare product features, etc.) may ease the shopping process while encouraging consumers to spend their effort on activities that would improve the shopping outcomes (e.g., identifying the best quality products).

Future research should extend this model. First, our study found that flow experiences and self-realization potential increase self-expressiveness in shopping. Future research may examine under what conditions shoppers are likely to experience flow in shopping and perceive a high potential for self-actualization through shopping. Second, the antecedents we tested in our model are mostly situational factors. Our model can be extended by identifying personality and individual difference variables that may be good predictors of self-expressiveness in shopping. The role of personality traits on shopping has largely been studied in the context of online shopping (Bosnjak et al., 2007; Wang et al.,
2006; Wang and Yang, 2008). Future research may examine the impact of personality traits on shopping in the context of physical stores. For instance, one may suggest that a personality factor such as extraversion may be predictive of self-expressiveness in shopping. Perhaps this may be due to the possibility that extraverts may be more inclined to go out and shop; shopping may be a conduit for interacting with people, and doing so meets the social needs of extraverts. Similarly, other well-known personality traits, such as openness to experience, conscientiousness, or agreeableness may have an impact on self-expressiveness in shopping. For example, people who are high on conscientiousness tend be more careful, efficient, and precise with their activities (Costa and McCrae, 1985). This may lead to high effort in a shopping context, which may also increase self-expressiveness in shopping. Being careful, efficient, and precise with activities may also make consumers become absorbed in the act of shopping (i.e., experience flow). Flow experience is likely to have a positive impact on selfexpressiveness in shopping.

Other predictors of shopping expressiveness may be cultural. One can hypothesize that smart shopper identity is much more evident in traditional societies that have clear gender roles-women and mothers take care of the family and shopping is part of their gender role. As such, demographic variables, such as gender, are consistent with the gender-role hypothesis. Third, with respect to the consequences of self-expressiveness in shopping, past research has focused on the dark side of shopping, such as compulsive shopping (e.g., Hosch and Loewenstein, 1991; Hirschman, 1992; Kwak et al., 2003; 2002; Mowen and Spears, 1999; Nataraajan and Goff, 1992; O'Guinn and Faber, 1989; Rindfleisch et al., 1997; Roberts et al., 2003; Roberts and Tanner, 2005). Future research may test the hypothesis that compulsive shopping moderates the relationship between perceived shopping contribution to life satisfaction and subjective well-being. In other words, as much as perceived shopping contribution to life satisfaction may contribute to subjective well-being, this effect may be significantly diminished when the shopper suffers from a shopping compulsion.

\section{References}

Anderson, J.C., Gerbing, D.W., 1988. Structural equation modeling in practice: a review and recommended two-step approach. Psychol. Bull. 103, 411-423.

Anderson, K.C., Knıght, D.K., Pookulangara, S., Josiam, B.M., 2014. Influence of hedonic and utilitarian motivations on retailer loyalty and purchase intention: a facebook perspective. J. Retail. Consum. Serv. 21, 773-779.

Arnold, M.J., Reynolds, K.E., 2003. Hedonic shopping motivations. J. Retail. 79, 77-95.

Babin, B.J., Darden, W.R., Griffin, M., 1994. Work and/or fun: measuring hedonic and utilitarian shopping value. J. Consum. Res. 20, 644-656.

Bäckström, K, 2011. Shopping as leisure: an exploration of manifoldness and dynamics in consumers shopping experiences. J. Retail. Consum. Serv. 18 (3), 200-209.

Belk, R.W., 1985. Materialism: trait aspects of living in the material world. J. Consum. Res. 12 (3), 265-280.

Bosnjak, M., Brown, C.A., Lee, D.-J., Yu, G.B., Sirgy, M.J., 2016. Self-expressiveness in sport tourism: determinants and consequences. J. Travel Res. 55, 125-134.

Bosnjak, M., Galesic, M., Tuten, T., 2007. Personality determinants of online shopping: explaining online purchase intentions using a hierarchical approach. J. Bus. Res. 60, 597-605.

Burroughs, J.E., Rindfeisch, A., 2002. Materialism and well-being: a conflicting value perspectives. J. Consum. Res. 29, 348-370.

Carpenter, J.M., Moore, M., 2009. Utilitarian and hedonic shopping value in the US discount sector. J. Retail. Consum. Serv. 16 (1), 68-74.

Costa, P., McCrae, R., 1985. The NEO personality inventory. Psychological Assessment Resources, Odessa, FL.

Czikszentmihalyi, M., 1990. Flow: The Psychology of Optimal Experience. Lidov: Noviny, Praha.

Csikszentmihalyi, M., 1997. Finding flow. Psychol. Today, 46-71.

Csikszentmihalyi, M., Csikszentmihalyi, I.S. (Eds.), 1992. Optimal Experience: Psychological Studies of Flow in Consciousness. Cambridge University Press.

Csikszentmihalyi, M., LaFevre, J., 1989. Optimal experience in work and leisure. J. Personal. Soc. Psychol. 56, 815-822. 
Davis, L., Hodges, N., 2012. Consumer shopping value: an investigation of shopping trip value, in-store shopping value and retail format. J. Retail. Consum. Serv. 19, 229-239.

Deci, E.L., Koestner, R., Ryan, R.M., 2001. Extrinsic rewards and intrinsic motivation in education: reconsidered once again. Rev. Educ. Res. 71, 1-27.

Diener, E., 1984. Subjective well-being. Psychol. Bull. 95, 542-575.

Diener, E., Suh, E.M., Lucas, R.E., Smith, H., 1999. Subjective well-being: three decades of research. Psychol. Bull. 125, 276-302.

El-Hedhli, K., Chebat, J.-C., Sirgy, M.J., 2013. Shopping well-being at the mall: construct, antecedents, and consequences. J. Bus. Res. 66, 856-863.

Fornell, C., Larcker, D., 1981. Evaluating structural equation models with unobservable variables and measurement errors. J. Mark. Res. 18, 39-50.

Guiry, M., Mägi, A.W., Lutz, R.J., 2006. Defining and measuring recreational shopper identity. J. Acad. Mark. Sci. 34, 74-83.

Hirschman, E.C., 1984. Experience seeking: a subjective perspective of consumption. J. Bus. Res. 12, 115-136.

Hirschman, E.C., 1992. The consciousness of addiction: toward a general theory of compulsive consumption. J. Consum. Res. 19, 155-179.

Hoffman, D.L., Novak, T.P., 1996. Marketing in hypermedia computer-mediated environments: conceptual foundations. J. Mark. 60, 50-68.

Hosch, S.J., Loewenstein, G.F., 1991. Time-inconsistent preferences and consumer self-control. J. Consum. Res. 17, 492-507.

Kasser, T., Ryan, R.M., 1993. A dark side of the American dream: correlates of financial success as a central life aspiration. J. Personal. Soc. Psychol. 65, 410-422.

Kwak, H., Zinkhan, G.M., Crask, M.R., 2003. Diagnostic screener for compulsive buying: applications to the USA and South Korea. J. Consum. Aff. 37, 161-171.

Kwak, H., Zinkhan, G.M., Dominick, J.R., 2002. The moderating role of gender and compulsive buying tendencies in the cultivation effects of TV shows and TV advertising: a cross-cultural study between the U.S. and South Korea. Media Psychol. 4, 77-111.

Mowen, J.C., Spears, N., 1999. Understanding compulsive buying among college students. J. Consum. Psychol. 8, 407-430.

Nataraajan, R., Goff, B.G., 1992. Manifestations of compulsiveness in the consumer marketplace domain. Psychol. Mark. 9, 31-44.

Nicolao, L., Irwin, J.R., Goodman, J.K., 2009. Happiness for sale: do experiential or material purchases lead to greater happiness? J. Consum. Res. 36, 188-198.

O’Guinn, T.C., Faber, R.J., 1989. Compulsive buying: a phenomenological exploration. J. Consum. Res. 16, 147-157.

Pavot, W., Diener, E., 2008. The satisfaction with life scale and the emerging construct of life satisfaction. J. Posit. Psychol. 3, 137-152.

Richins, M.L., Dawson, S., 1992. A consumer values orientation for materialism and its measurement: scale development and validation. J. Consum. Res. 19, 303-316.

Rindfleisch, A., Burroughs, J.E., Denton, F., 1997. Family structure, materialism, and compulsive consumption. J. Consum. Res. 23, 312-325.

Roberts, J.A., Manolis, C., Tanner, J.F., 2003. Family structure, materialism, and compulsive consumption: a re-inquiry and extension. J. Acad. Mark. Sci. 31 300-311.

Roberts, J.A., Tanner, J.F., 2005. Materialism and family structure-stress relation. J. Consum. Psychol. 15, 183-190.

Rojas, M., 2006. Life satisfaction and satisfaction in domains of life: is it a simple relationship? J. Happiness Stud. 7, 467-497.

Rook, D.W., Fisher, R.J., 1995. Normative influence on impulsive buying behavior. J. Consum. Res. 22 (3), 305-313.

Shah, J.Y., Kruglanski, A.W., 2000. The structure and substance of intrinsic motivation. In: Sansone, C., Harackiewicz, J.M. (Eds.), Intrinsic and Extrinsic Motivation: The Search for Optimal Motivation and Performance. American Press, San Diego, pp. 106-130.

Sharp, E.H., Coatsworth, J.D., Darling, N., Cumsille, P., Ranieri, S., 2007. Gender differences in the self-defining activities and identity experiences of adolescents and emerging adults. J. Adolesc. 30, 251-269.

Shim, S., Dubey, S., 1995. Conceptualization and measurement of perceived consumer knowledge and skills in apparel products: an exploratory study among college students. Fam. Consum. Sci. Res. J. 23, 227-248.

Silvera, D.H., Lavack, A.M., Kropp, F., 2008. Impulsive buying: the role of affect, social influence, and subjective well-being. J. Consum. Mark. 25, 23-33.

Sirgy, M.J., 2012. The Psychology of Quality of Life: Hedonic Well-Being, Life Satisfaction, and Eudaimonia. Springer Publishers, Dordrecht.

Sirgy, M.J., Gurel-Atay, E., Webb, D., Cicic, M., Husic-Mehmedovic, M., Ekici, A., Herrmann, A., Hegazy, I., Lee, D.J., Johar, J.S., 2013. Is materialism all that bad? Effects on satisfaction with material life, life satisfaction, and economic motivation. Social. Indic. Res. 110, 349-366.

Sivadas, E., Machleit, K., 1994. A scale to measure the extent of object incorporation in the extended self. In: Park, W., Smith, D.C. (Eds.), Proceedings of the American Marketing Association Winter Conference. American Marketing Association, Chicago, pp. 143-149.

Swinyard, W.R., 1993. The effect of mood, involvement, and quality of store experience on shopping intentions. J. Consum. Res. 20, 271-280.

Telfer, E., 1980. Happiness. St. Martin's Press, New York.

Van Boven, L., Gilovich, T., 2003. To do or to have? That is the question. J. Personal. Soc. Psychol. 85, 1193-1202.

Wakefield, K.L., Baker, J., 1998. Excitement at the mall: determinants and effects on shopping response. J. Retail. 74, 515-540.

Wagner, T., 2007. Shopping motivation revised: a means-end chain analytical perspective. Int. J. Retail Distrib. Manag. 35, 569-582.

Wang, S., Wang, S., Wang, M.T., 2006. Shopping online or not? Cognition and personality matters. J. Theor. Appl. Electron. Commer. Res. 1, 68-80.

Wang, C., Yang, H., 2008. Passion for online shopping: the influence of personality and compulsive shopping. Social. Behav. Personal.: Int. J. 36, 693-706.

Waterman, A.S., 1990. Personal expressiveness: philosophical and psychological foundations. J. Mind Behav. 11, 47-74.

Waterman, A.S., 1993. Two conceptions of happiness: contrasts of personal expressiveness (eudaimonia) and hedonic enjoyment. J. Personal. Soc. Psychol. 64, 678-691.

Waterman, A.S., 2005. When effort is enjoyed: two studies of intrinsic motivation for personally salient activities. Motiv. Emot. 29, 165-188.

Waterman, A.S., 2008. Reconsidering happiness: a eudaimonist's perspective. J Posit. Psychol. 3, 234-252.

Waterman, A.S., Schwartz, S.J., Conti, R., 2008. The implications of two conceptions of happiness (hedonic enjoyment and eudaimonia) for the understanding of intrinsic motivation. J. Happiness Stud. 9, 41-79. 